\title{
RESEARCHER-TEACHER COLLABORATION IN ADOPTING CRITICAL CONTENT AND LANGUAGE INTEGRATED LEARNING (CLIL): PROCESSES, CHALLENGES AND OUTCOMES
}

\section{COLABORAÇ̃̃̃O ENTRE PESQUISADORA E PROFESSORA NA ADOÇÃO DE UMA ABORDAGEM INTEGRADA DE CONTEÚDO E DE LÍNGUA (CLIL): PROCESSOS, DESAFIOS E RESULTADOS}

Kao Chia-Ling Gupta ${ }^{*}$ **

\begin{abstract}
While the growing trend of internationalisation and globalisation has been addressed by policymakers and the interest in adopting the CLIL approach has increased, calls have been made for uncovering how teachers can develop ways of designing and implementing corresponding materials and engage students in such an approach. This is a collaborative study that explores in details, based on the Interactional Ethnographic approach, the processes of how the researcher and the teacher worked together in an egalitarian setting to design and carry out a CLIL unit. Throughout this five-month research involved with multiple stages of development of resources, with an English teacher and sixteen of her Grade 4 students, I have made visible the multiple forms of our collaboration and the important issues for consideration with implications in closing the gap between research and practice, and between design and implementation. Finally, I conclude that the researcher-teacher collaborative approach laid out by event maps could be an innovative way to re-examine and reflect upon the dynamics between the researcher and the researched by acknowledging and fortifying the bond between the two.
\end{abstract}

Keywords: content and language integrated learning (CLIL); interactional ethnography (IE); collaborative research

\section{RESUMO}

Enquanto a crescente tendência de internacionalização e globalização tem sido endereçada por criadores/as de políticas públicas e o interesse em adotar a Abordagem Integrada de Conteúdo e de Língua (CLIL) aumentado, observa-se também a necessidade de compreender

\footnotetext{
* Faculty of Education, University of Hong Kong, Hong Kong SAR, P. R. kclgupta@connect.hku.hk Orcid: https://orcid.org/0000-0001-7980-528X

** I want to thank Prof. Angel Lin for supervising me throughout the development of this research. I am also grateful for the reviewers' comments and suggestions, which helped me improve the quality of the article.
} 
como os/as professores/as podem desenvolver formas de desenhar e implementar materiais de forma a engajar alunos/as nessa abordagem. Este é um estudo colaborativo que, com base na abordagem da Etnografia Interacional, explora em detalhes processos em que a pesquisadora e a professora trabalharam juntas em um contexto igualitário para desenhar e implementar uma unidade CLIL. Durante estes cinco meses de pesquisa envolvida em estágios múltiplos de desenvolvimento de recursos, com uma professora de inglês e dezesseis de seus alunos/as do quarto ano, tornei visíveis as nossas múltiplas formas de colaboração e considerei questões importantes que trazem implicações para diminuir a lacuna entre pesquisa e prática e entre desenho e implementação. Finalmente, concluo que a abordagem colaborativa entre pesquisadora e professora orientada pela construção de mapas de eventos pode constituir uma forma inovadora de reexaminar as e refletir acerca das dinâmicas entre pesquisadora pesquisada na medida em que fortalece a conexão entre ambas.

Palavras-chave: abordagem integrada de conteúdo e de língua (CLIL); etnografia interacional $(\mathrm{EI})$; pesquisa colaborativa

\section{INTRODUCTION}

In response to the trend of globalisation, there has been extensive research that examines the nature and development of English linguistic capital. One area of study has been English medium education. In Taiwan, where English is used as a language for international communication, policymakers have created educational initiatives to support primary and secondary schools to address this issue. Yet to date, there is limited research on how teachers are introduced to developing ways of integrating English language teaching with existing curriculum requirements, or how they can engage students in learning ways of communicating through English and engaging with English language texts. In Taiwan, the development of the content and language integrated learning (CLIL) approach has been a response to the global trend. CLIL refers to an educational approach teaching content through an additional language of students with a dual focus on content and language learning. While CLIL has been widely recognised due to its nature of dual learning goals, the resources in Taiwan necessary to put CLIL into practice are limited.

To address the challenge of implementing CLIL with teachers in Taiwan, given the limited resources and the need for understandings of how to support teachers in developing a CLIL curriculum in their classes, I developed a collaborative research process with a language teacher to create, design, implement and reflect upon a CLIL unit aiming at enhancing students' critical awareness. This collaboration was undertaken across five months and involved multiple stages of development of resources, as well as instructional processes as I worked collaboratively to develop a CLIL program with her students. As part of this process, I assumed the role of an ethnographer to trace the developing decisions made and the stages of the 
CLIL process critical to the construction and implementation of this curriculum through the reflexive approach developed to support Ms Hou (a pseudonym) in transforming her current curriculum approach to a CLIL approach, as framed by the reform policy in Taiwan.

To unfold what, when, why particular actions were taken throughout this collaborative research, I adopted an Interactional Ethnographic approach to the collaborative research. The Interactional Ethnographic logic of inquiry (CASTANHEIRA, CRAWFORD, DIXON, \& GREEN, 2000), as presented in this study, framed the approach I undertook to trace multiple phases and stages of collaboration and the implementation of a CLIL unit. The study of the developing process is presented in two parts. In Part 1, I present the analysis of the dialogic processes that the teacher and researcher engaged in across the five months of the project that led to the development of a CLIL unit of instruction. In Part 2, I present an analysis of students' perspectives and processes of engagement in this unit. Through these two sets of analyses, I make visible multiple dimensions identified that this form of collaboration entailed, including the nature and role of the reflexive dialogues that I engaged in with Ms Hou as she constructed a CLIL unit of instruction, and how our decisions and actions within and across times and events contributed to decision-making throughout our collaboration. Our decisions then played a role in shaping students' performance in the CLIL unit. Through this approach, I demonstrate the process of constructing event maps as an innovative way to re-examine and reflect upon the dynamics between the researcher and the researched and the bond that developed between the two to support this dynamic and complex process at the centre of the Taiwan reform initiative corresponding to globalization and internationalization.

\section{THE ROOTS OF THE POLICY CONTEXT: FRAMING CLIL AS A REFORM INITIATIVE}

In response to the trend of globalisation, the world has been emphasising internationalisation. One way to address the current trend toward internationalization is through education, particularly language education. In Taiwan, government officials, teachers and parents have been concerned about whether and how their students and their children can, through educational initiative, develop English linguistic capital. This growing concern has led to efforts at the policy level to promote students' English language ability in Taiwan, as well as other countries. For example, Lin (2016) identified movements that are promoting English as a medium of education in non-English speaking countries, an approach being implemented 
in many Southeast Asian societies, whether or not the society has been part of colonial contexts in which English (British and US) was a language of education.

The current policy initiatives designed to introduce English as a medium of instruction had their roots in 2002 when Taiwan joined the World Trade Organisation (WTO), where internationalisation has been heavily emphasised. The actions taken by Taiwan to enhance internationalisation, for example, has focused on tertiary education, where teachers are offered English-medium courses (HUANG, 2014). This process has been especially encouraged by the Ministry of Education in Taiwan in response to the current global trends.

Another contributing factor that has led to the need for reforms to support participation in global economies is the fact that the high-stakes examinations within the schooling system are conducted in Mandarin Chinese, and that English is not yet pervasively used in this schooling context; primary and secondary education in Taiwan is mostly provided in Chinese (Mandarin). Only recently, when Taiwan started an education reform that moved the school requirements from Nine-years of basic education to Twelve-years of basic education, has the integration of English and content knowledge been emphasized in new curriculum guidelines. As released by National Academy for Educational Research in Taiwan in November 2012, the new curricular guidelines feature the promotion of learning progression and cross-field integration, as well as the emphasis on applying knowledge to real-life scenarios, the development of school-based curriculum and the implementation of personalised learning. To respond to this reform, as a member of the review committee on English textbooks since 1999 under National Academy for Educational Research, Taiwan, Yeh (2016, p. 144) proposed eight aspects of developing English textbooks:

(1) a progressive and integrative framework for textbook writing; (2) integration of different curriculum ideologies; (3) introduction of learning strategies and autonomous learning; (4) development of thinking skills; (5) promotion of reading strategies and extensive reading; (6) clear roles assigned to phonics and phonetic symbols; (7) contextualization of grammar instruction, as well as distinction between structure for production and structure for recognition; and (8) flexible materials for differentiated instruction.

Furthermore, the Taiwan government's increasing emphasis on the English language can be more explicitly seen in the fact that in 2015, the Office of English as the Second Official Language was established by the Tainan City Government in Taiwan. This Office was established to make Tainan City, which is a special municipality and the highest level of local government in Taiwan, into a fully bilingual environment (in English and Mandarin) within ten years, by 2025 (LEE \& YANG, 2018). To achieve this goal, providing bilingual education has been defined 
as one of the most important approaches to building internationalization within Taiwan. In particular, this Office plans to adopt what has been described as a content and language integrated learning (CLIL) approach to realizing bilingual education.

In Taiwan, the fact that there are multiple languages including Mandarin, Taiwanese Hokkien and Hakka, among others, and that English has been used as an international language for international communication, leads to a debate about whether English is an official "second" language, a lingua franca, or rather a particular form of linguistic capital. The challenge in this debate is grounded in the fact that until recently, English has not been a language of schooling, a further issue that makes this government movement both challenging and open to debate, not only in Taiwan but globally (See Kachru, 1992 for a history of issues of world Englishes).

Given that the Taiwanese government has created a series of education reforms that include expanding basic education in Taiwan from the current Nine-year basic education to Twelve-year basic education and from non-bilingual education (Mandarin) to bilingual education (Mandarin and English), there is an urgent need for research on a range of educational issues, such as curriculum development, teacher training, design of assessments, educational policies, etc. This state of reform, therefore, has framed the need for this study, which is designed to explore the challenges faced by teachers, curriculum leaders, and school leaders in seeking to address the mandate for the CLIL approach to bilingual education.

\section{THE DESIGN OF THE STUDY AS A COLLABORATIVE PROCESS}

The foundation for this study, therefore, is grounded in response to this policy that has led to a series of conferences, workshops, seminars, etc. organised by universities to provide support for primary school and secondary school teachers in Taiwan to implement the CLIL approach in their lessons. It was at one of these workshops in which I joined as a facilitator that I located a teacher who was willing to participate in my research focusing on CLIL as a developing instructional approach. During two workshops organised in August and December, respectively in 2018, by a university in Taipei, Taiwan, and conducted by my doctoral advisor, Professor Angel Lin, I was introduced as a $\mathrm{PhD}$ student conducting research on the implementation of critical CLIL, who was seeking to identify schools, teachers and students that would be willing to engage with me in this research. In addition to my identity as a researcher, who would engage with teachers at a school site, I was introduced as a consultant who would have expertise in researching CLIL 
instruction and development and would guide participating teachers' as they prepared, designed and implemented CLIL materials.

Ms Hou (a pseudonym), a fourth-grade experienced language teacher agreed to support my study and to collaborate with me as she developed a CLIL process in her class based on our common understanding of the need to develop research-based awareness of CLIL processes and its relationship to students' access to English as a medium of content instruction. As agreed, our goal was to examine what, how, when, and why particular decisions were made to get a deeper understanding of the developing social space. The following questions guided our collaborative research and process of collaboration:

1) How did the researcher-teacher collaborative approach impact the decisions made throughout the creation of such social spaces?

2) How was the researcher-teacher collaboration formed to increase the critical awareness of students?

In the remaining sections of this research report, I progressively unfold our decisions and actions throughout the collaborative processes. Guided by an IE logic-of-analysis, I present the processes of analysis of data collected from formal and informal interviews, meeting minutes, lesson observations, feedback sheets, and teaching and learning artefacts. This logic-of-analysis involved the production of Key Events Map (KELLY \& CHEN, 1999) to (re)present the timeline of the overall ethnographic study and to define entry points for an analysis of developing the partwhole/whole-part relationship (GREEN, DIXON \& ZAHARLICK, 2005; GREEN, SKUKAUSKAITE \& BAKER, 2012) of our developing collaborative processes.

To make transparent my research process that was guided by the IE logicof-analysis, I present the basis for constructing a series of Key Event Maps (KELLY \& CHEN, 1999), and for constructing a timeline of the developing events undertaken by the researcher and teacher in this collaborative ethnographic study to frame the part-whole/whole-part relationship (GREEN, DIXON \& ZAHARLICK, 2005) within and across times and events analysed. The IE logic-of-analysis, therefore, guided my process of uncovering the processes and phases of our collaboration. Data for this analysis involved the collection and construction of data constructed from formal and informal interviews, meeting minutes, lesson observations, feedback sheets, and teaching and learning artefacts. These records and forms of data provided a basis, as I will demonstrate, for tracing and (re)constructing our decisions and actions throughout the collaborative processes as a potential foundation for future work. This process is designed to lay a foundation for future studies that examine if, 
how and whether another group of students and their teacher(s) will accomplish or engage in a similar or the same process while adopting a CLIL approach.

\section{THE CLIL APPROACH: WHAT, WHY AND HOW}

In this section, I present a review of how CLIL has been defined. CLIL, content and language integrated learning, was described by Coyle, Hood, and Marsh (2010, p. 1), as a "dual focused educational approach in which an additional language is used for the learning and teaching of both content and language." In other words, CLIL is an approach to teaching content (often, but not limited to), the subject knowledge through a language other than the first language of learners. Thus, the aim of adopting CLIL is twofold. Firstly, it seeks to enhance learners' foreign language competence; at the same time, secondly, it aims to facilitate the learning of content.

The rationale behind CLIL can be explained by Halliday's (1993, p. 93-94) arguments about language and meaning. Human learning is said to be "a process of making meaning." Thus, language is "not a domain of human knowledge (except in the special context of linguistics, where it becomes an object of scientific study); language is the essential condition of knowing, the process by which experience becomes knowledge." Language, when taken as a resource to construct meaning, is then inextricably interwoven with content. This inseparable relationship between language and content is echoed by Mercer's (1995) Vygotskian perspective of depicting language as a medium of knowledge construction.

While language and content are considered to be integrated, there is a variation in to what extent they are integrated. Bentley (2010) has put forth a continuum which is made up of "soft CLIL" at one end and "hard CLIL" at the other. The former approach is often adopted by language teachers as a way to integrate content into their lessons, so it is language-led, while the latter is commonly practised by content teachers, so it is subject-led. In a study conducted in Japan, Ikeda (2013, p. 32) defined soft CLIL as "a type of content and language integrated instruction taught by trained CLIL language teachers to help learners develop their target language competency as a primary aim and their subject/theme/topic knowledge as a secondary aim." In the current research context, the CLIL practices were engaged by a language teacher, thereby situating this study towards the "soft CLIL" end of the continuum.

Previous studies on CLIL commonly adopted case study, defined by Stake (1995, p. xi) as "the study of the particularity and complexity of a single case," 
to examine teacher education for CLIL, e.g. the trajectory of becoming a CLIL teacher through reflection (ESCOBAR URMENETA, 2013), conceptualisation (KARABASSOVA, 2018), teacher identity (HE \& LIN, 2018) and beliefs and awareness (LO, 2019). It is believed that a case study is a suitable method, in that through the selection of a case, a close examination can be undertaken. In particular, Escobar Urmeneta (2013) and He and Lin (2018) incorporated an ethnographic perspective in their case studies on interpreting their data. Ethnography has been differently defined by scholars in different disciplines. When understood as a logic of inquiry, ethnography is regarded as "the study of cultural practices" (GREEN ET AL., 2005, p. 69) to uncover the practices of a particular group. As ethnographers, therefore, they can delineate the patterns of their collected data as insiders (GREEN ET AL., 2005).

As mentioned in Introduction, this study intends to examine critical issues faced by teachers and curriculum consultant through an ongoing dialogue as they engage in co-designing CLIL materials with the teacher in the context of this school reform. Thus, the emphasis on the processes of this research renders IE a warrantable approach to collecting and analysing data across times and events based on which I draw conclusions.

\section{THE MULTIMODALITIES-ENTEXTUALIZATION CYCLE (MEC) AS A PEDAGOGICAL FRAMEWORK}

To further frame key conceptual issues that guide the process undertaken to develop the CLIL unit of instruction in this study, I now turn to a critical argument about the nature of texts that guided Ms Hou's and my dialogues about the developing resources. Lin's $(2015,2016)$ Multimodalities-Entextualisation Cycle (MEC), shown in Figure 1, was adopted as the curriculum genre (CHRISTIE \& MARTIN, 2005; ROSE \& MARTIN, 2012) to guide the design of the intervention learning units in this study. The MEC was developed by Lin $(2015,2016)$ to frame the potential of using students' first language (L1) as a scaffolding process during instruction. The MEC process and logic is presented in Figure 1 


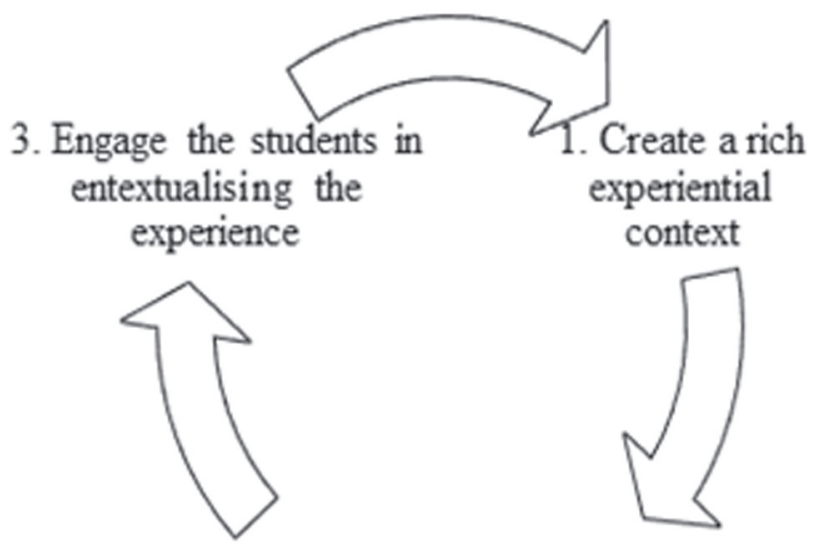

2. Engage the students

in reading and notemaking

Figure 1. The Multimodalities-Entextualisation Cycle (MEC). Adapted from Language across the curriculum \& CLIL in English as an additional language (EAL) contexts: Theory and practice (p. 103), by A. M. Y Lin, 2016.

As indicated in Figure 1, the core rationale for engaging in this cycle is "to use L1 and L2 everyday language and genres together with multimodalities ... to scaffold students' learning of L1 and L2 academic languages and genres" (LIN, 2015 , p. 86). The emphasis on using both L1 and L2 in the process of engaging students in CLIL and other processes is to support the inclusion of rich and multimodal resources as scaffolding for students' listening/reading and speaking/ writing processes.

As represented in this cycle of the process, the MEC can be iterated multiple times. This iterative process makes visible how the MEC contributes as a conceptual framework to guide the pedagogical design of CLIL lessons. As we will demonstrate in the analysis sections that follow, the three stages of this approach frame the final stages of analysis, as well as development, given that the process of engaging students in CLIL units of study begin with creating a rich content topicbased context, followed by engaging students in reading/note-taking on the topic, and finally supporting students to entextualise their experience and learning on that topic through crafting a spoken/written/multimodal text for a specific audience. While the MEC framework was used to guide the design of each CLIL unit, as we will make visible, the actual process that we developed involved adaptations of MEC guidelines based on the participating teacher's concerns of how to integrate 
CLIL and the MEC process in the context of the reform guidelines as well as the existing curriculum defined by the Ministry of Education.

\section{PARTICIPANTS, PROCEDURE AND DATA}

The research reported in this paper was undertaken over five months between February and June 2019 at a primary school. The participants, whose consent to take part in this study was obtained, were a certified English teacher (Ms Hou), with 25 years of experience, and students in her class. In total, sixteen of her Grade 4 students aged from 9 to 10 participated in this study.

The research process began with a "needs analysis" through interviews and questionnaires to increase my familiarity with the participating teacher and students. I treated their responses as the baseline data related to the teacher's and students' perspectives on their regular English lessons and their general attitudes towards addressing social issues in English lessons. This paper reports the first two procedures of the study, the preparation stage and the piloting stage, comprising two iterations of development, tryouts, evaluation and refinement, with the second tryout as the focal point. Figure 2 shows the research procedure. A total of three lessons, each of which lasting 40 minutes, were spent on the first and the second tryouts with Ms Hou and her students. To reflect on the learning activities, the learning materials, the students' reaction and performance, I carried out reflective discussions with Ms Hou and analysed students' in-class performance and their learning artefacts at the end of each unit (tryout).

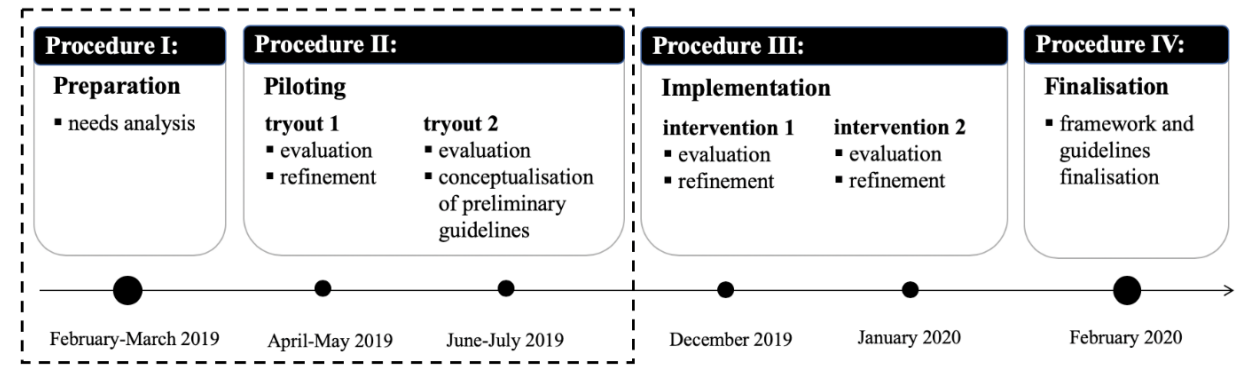

Figure 2. The research procedure

The different types of data collected for analysis included videos taped during classroom observations; audios recorded from interviews and classroom observations; learning artefacts such as posters, drawings and written works; 
teaching artefacts such as worksheets, handouts, and PowerPoint slides co-created by Ms Hou and me; students' written record generated from the questionnaire and feedback forms; and textual record of informal discussions saved and downloaded from emails and the mobile communication application. Table 1 provides a list of data for analysis in details.

Table 1. Types of research data for analysis

\begin{tabular}{ll}
\hline Category & Content \\
\hline Video & English lesson observations \\
Audio & English lesson observations \\
& Interviews with Ms Hou \\
& Interviews with students \\
Learning artefacts & Posters, drawings, writing \\
Teaching artefacts & Worksheets, handouts, PowerPoint slides \\
Written record & Questionnaire, feedback form \\
Textual record & Discussions and communication \\
\hline
\end{tabular}

\section{MAKING VISIBLE THE COLLABORATIVE RESEARCH PROCESS}

During the five months of collaboration with Ms Hou, through participant observations and artefact analyses, I identified the key events that would facilitate an understanding of how our collaboration developed throughout the research. Using the event map of the part-whole/whole-part relationship (GREEN ET AL., 2005), as shown in Figure 3, I was able to locate, identify, explore and analyse this process. Read from top to bottom, the event map shows the levels of data generated from macro to micro perspectives. 


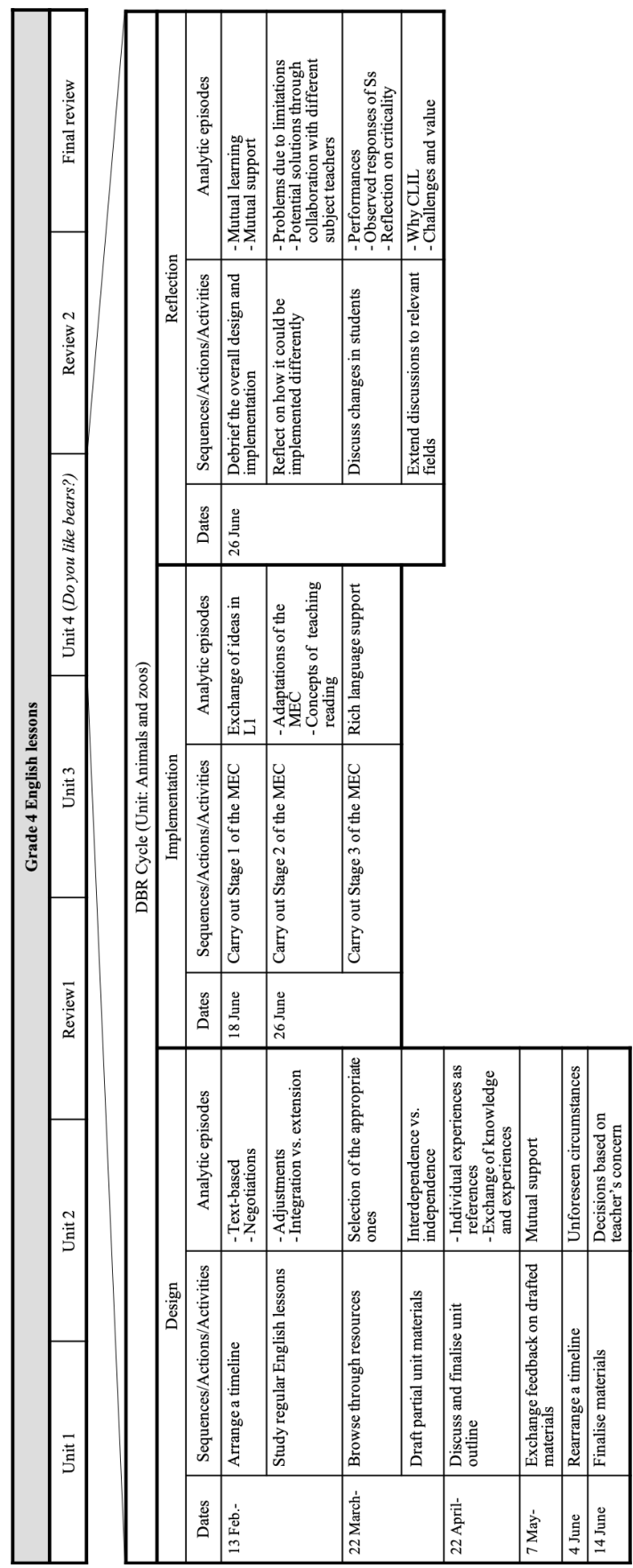

Figure 3. Event map of the researcher-teacher collaboration on a CLIL unit 
As indicated in Figure 3, the first row Grade 4 English lessons signals in which context the CLIL materials were being developed. Since Ms Hou conducted her lessons based on official textbook units, and that I did not intend to intervene her arrangements of lessons throughout the semester, or in the education received by students given that MS Hou was following the national guidelines, the second row shows the lesson units that followed the organisation of the textbook used in that semester. This sequence was based on the requirement that in the semester from January to June 2019, Ms Hou had to complete four units with her Grade 4 students, along with three review lessons. Together, the first and the second rows provide a (re)construction of the first level of curriculum design.

I then zoomed in on Lesson 4 (Do you like bears?) as the focused episode as an anchor because the construction of that CLIL unit provided rich instances of collaboration and concrete evidence of students' critical thinking skills. The third row indicates my adoption of the design-based research (DBR) (BROWN, 1992) process to guide the analysis of our stages of collaboration, given that DBR is collaborative (EDELSON, 2002) and iterative (VAN DEN AKKER, GRAVEMEIJER, MCKENNEY, \& NIEVEEN, 2006) in nature. Through this process, I make visible how this research journey is seen as a recursive one, not a linear one. Finally, the fourth row comprises the design, implementation and reflection stages. The process of event mapping, as indicated in Figure 3, enabled me to situate this research and the data analysed with increasing details.

For each stage of the DBR research, three items guided me in (re)constructing the events in great detail: 1) the dates (or a period, denoted by " ${ }_{-}$) on which the key events took place, 2) the sequences/actions/activities showing the key events, and 3) the analytic episodes which are the potential points for analysis. As indicated in Figure 3, under the second column of each stage, indicators of changes from one action to another are presented. The key events analysed were essential to my understanding of what and how actions were taken that supported the identification of potential areas of new knowledge, misunderstandings, conflicts, agreements or compromises throughout my collaboration with Ms Hou. In the Analytic episodes column, I provide annotations of my interpretation of the data developed analytically.

In the following sections, I will provide a detailed analysis of how Ms Hou and I worked together on the development of one CLIL unit with the theme of Animals and Zoos. The theme was decided under two main criteria: 1) it is related to the textbook lesson, in this case, Lesson 4 on animals and 2) the theme raised was debatable so that students would be provided with the opportunities to perform 
critical thinking. This theme required the teacher and students to (re)consider the necessity of a zoo.

On 13 February, as soon as I received the consent of the school principal, Ms Hou and one class of her students, I started proposing a timeline to facilitate the development of the research process and to ensure that each step could happen at times appropriate for $\mathrm{Ms} \mathrm{Hou}$, and for my schedule as a $\mathrm{PhD}$ student at the university. Since in February and March, we were unable to conduct face-to-face discussions, our discussions were mainly carried out online using text-messages supported by a communication application. The limitations of text-based discussions soon became evident to me. For example, providing or receiving timely responses became a challenge, not due to feasibility but due to a range of conditions leading to uncertainty. For example, while technology allows for instant communication, it eventually is up to the agents when they would read and respond to a message. Secondly, misunderstanding could and did arise from texts and emoticons. Thus, it took as long as a month through ongoing negotiations to come up with a timeline for our formal collaboration, and even then, I later found this timeline open to renegotiation.

Throughout this phase of the discussions, I had assumed that time was something that could be controlled and would support the development of design materials based on a specific number of lessons allocated. This assumption, I learned, ignored the fact that DBR as a framework, is most often "carried out in the messy situations of actual learning environments" (COLLINS, JOSEPH, \& BIELACZYC, 2004, p. 19), and may vary even before the implementation of an intervention is conducted. Furthermore, analysis of the collaborative processes led to an understanding that throughout this process Ms Hou, the teacher, stayed uncertain as to how many and when the units could be done, as captured in the following statement from Ms Hou during a reflection: "it really depends on the depth of learning contents and the difficulty of assigned tasks".

Another factor influencing the actual timeline was our agreement that the lesson topics had to be ones covered in the curriculum guide proposed by the Ministry of Education. Based on this principle, both Ms Hou and I worked on identifying potential and possible themes that could be used to generate CLIL materials that would allow students to discuss social issues using critical thinking skills. During this phase of the developing project, I examined the learning objectives of each lesson listed in the textbook to familiarise myself with the current English lessons delivered at the primary education level. Through this analysis, I learned that the themes covered in Grade 4 textbooks range from weather, 
clotbing, food to animals, and were confined to themes concerning Basic Interpersonal Communication Skills, BICS (CUMMINS, 1981). I also learned that the policy framed the following process: English lessons are delivered at public schools starting at Grade 3, and one to two lessons are presented per week, in the city where this research took place. However, However, in the focus group interviews I conducted before the delivery of CLIL lessons, students displayed high levels of thinking on issues of their interest beyond those anticipated by the textbook. This unanticipated difference in assumed and actual levels of thinking visible in the lessons that integrated social issues into English lessons was also confirmed by Ms Hou and provided validation for the CLIL process. The question, however, arose during our conversations as to whether and/or how the CLIL lesson would be adopted, e.g. as a replacement of the regular lessons or as an add-on to it, a question that frames areas for further study.

As indicated further in Figure 3, on 22 March, after more than a month, we engaged in the next phase of identifying potential resources, i.e. we started browsing through and collecting resources relevant to the chosen topic-Animals and zoos but were soon overwhelmed by the enormous amounts of information and opinions available. The difficulty in selecting the appropriate ones soon increased. While ideas were "brewing," I also started drafting some materials to turn our ideas into concrete materials. At this stage, my relationship with Ms Hou varied and thus raised new questions to address. For example, Ms Hou exclaimed that she was stuck in preparation for the CLIL materials with the theme on Zoos, so I offered to come up with a draft. These steps as separate segments of the whole process, involved different levels of independence and interdependence (JOHNSON \& JOHNSON, 1989), with the teacher and I working individually towards the same goals while making decisions drawing on each other's actions and thoughts.

During this period, we remained in touch and shared thoughts, inspirations and concerns. Although holding a discussion, especially a face-to-face one, may be more efficient, I considered maintaining this intensive, collaborative and supportive relationship as equally important and helpful, for it created a zone in which random and brewing thoughts could be "tossed, caught and reacted to" not just in between us, but also within oneself. Excerpt 1 below makes visible this dialogic process through a (re)presentation of our conversation on a communication app extracted from the online chat history. This excerpt provides an example of how Ms Hou questioned her own idea by instantly reflecting upon her idea with text messages delivered to me. Excerpt 1, therefore, provides evidence that at times reflection 
was done not only when talking to oneself but also while talking about an idea with someone else.

Excerpt 1. Reflection through the delivery of messages

\begin{tabular}{lll}
\hline Timestamp & Sender & Discourse \\
\hline 17:36 & Researcher: & $\begin{array}{l}\text { I will browse through some resources and materials first, and } \\
\text { create an outline based on Prof. Lin's MEC for you as a reference. }\end{array}$ \\
18:59 & Ms Hou: & $\begin{array}{l}\text { That'd be great! } \\
\text { I9:03 }\end{array}$ \\
Ms Hou: & $\begin{array}{l}\text { I've got an idea. Write out the features of animals in sentences } \\
\text { and scatter those sentences. Allow students to read and sort } \\
\text { them. But then this way seems not as relevant to issues. }\end{array}$ \\
& Ms Hou: & $\begin{array}{l}\text { Social issues. } \\
\text { 19:03 }\end{array}$ \\
& & Friday, 22 March 2019 \\
\end{tabular}

On 22 April as indicated in Figure 3, two months after our first online contact about this study and development process, we had the chance to hold a face-toface meeting during which we discussed and finalised the outline of the lessons. For about half an hour, we discussed the articles to be adopted as reading resources, types of class activities to be held, critical issues for students to think about, learning objectives to achieve, target sentence patterns and vocabulary words students have acquired from the past, and ways to create opportunities for the usage of students' current English skills. Excerpt 2 indicates that we found ourselves at ease while proposing ideas, raising questions, casting doubts, questioning the purposes, etc. Further, Excerpt 2 provides an example of how Ms Hou and I, through a dialogue, enriched our ideas. Excerpt 2, therefore, makes visible that our discussion and form of collaboration was a horizontal one, forming a reciprocal process, despite our diverse backgrounds and roles.

\section{Excerpt 2. Discussion: enriching each other's ideas}

1 Ms Hou: The first lesson of this book focuses on actions, which I thought could be included.

2 Researcher: On verbs?

3 Ms Hou: Right, verbs. They've also learned can, so then...

4 Researcher: So, I guess this part could be about the features of animals.

5 Ms Hou: Right, right, right, exactly the features of animals, like where they live, or I've been thinking about which colours, what they can do and what they have. Uhoh, they may not have learned the usage of have. But still, let's see which ones could work. Do you think this unit could be a review? 
The following two excerpts make visible an additional pattern to our collaboration. Analysis of Excerpts 3-1 and 3-2 made visible that we also used our assumptions about processes and our personal experiences to challenge each other's ideas.

\section{Excerpt 3-1. Discussion: expressing a negative attitude to an opinion (I)}

1 Ms Hou: Alright, I've seen one, something interesting, comparing the Chinese and English idioms about animals. But then it's more about cultures, the idioms about animals, the Chinese idioms. It could be off-topic, though.

2 Researcher: I suppose idioms would be challenging for them.

3 Ms Hou: It's irrelevant, way too irrelevant.

Analysis of Excerpt 3-2 provided evidence of an increasing level of agreement that reflected how when one of us proposed an idea (utterance 1) and provided some background information (utterance 3 ), the other added in new information by seeking confirmation (utterance 2) and offering a suggestion (utterance 4). Finally, this excerpt ends with a new idea inspired by the dialogue. Although a limitation was found, along with the new ideas (utterance 5), the teacher seemed to hold a positive attitude towards new opportunities.

In contrast, Excerpt 3-2 provides evidence of how the teacher and I took advantage of our individual experiences to raise doubts concerning the feasibility of putting forth particular ideas. For example, drawing on my understanding of an idiom, which requires linguistic and cultural knowledge to be understood, I claimed that the idea of comparing Chinese and English idioms about animals as the learning activity would be too challenging (utterance 2, Excerpt 3-1)

\section{Excerpt 3-2. Discussion: expressing a negative attitude to an opinion (II)}

1 Ms Hou: Ok, go on. But I think something's stuck. After comparing humans and animals, we may find that... I think we can guide students; there are things some animals can do while humans cannot. So? Humans are seen as...

2 Researcher: The smartest.

3 Ms Hou: Right. We have all...When we have control of the resources on the earth, could we then decide the other animals'...

4 Researcher: Exactly, that's it, posing an open-ended question to students.

5 Ms Hou: Ok, so this is it. Alright then, but they will definitely say "no" because they know what an ideal answer is. Do you know what I mean?

6 Researcher: What will they say? 
7 Ms Hou: I mean, they've been trained, knowing that the answer must be negative to this type of question.

8 Researcher: Meaning we are not supposed to (control animals)?

9 Ms Hou: That's right.

10 Researcher: Well then, based on their negative response, we further ask why there's someplace like a zoo.

11 Ms Hou: Why do we keep animals in a zoo?

12 Researcher: Right.

13 Ms Hou: And then guide them to think about it.

14 Researcher: Or why are some animals endangered? Could it be due to some humans' activities?

As further indicated in Excerpt 3-2, Ms Hou raised an issue (utterance 5, Excerpt 3-2) based on her familiarity with her students and years of teaching experience, indicating that her students would definitely answer the moral question (With all the resources in band, can bumans take control of animals?) in the "correct" way. She attributed this to the fact that they have been "trained" in telling which behaviour is morally (in)correct. The three excerpts made visible different ways in which our exchange of knowledge created opportunities to reflect on our personal understandings and assumptions, the experience of students in the historical program, and what might be potentially possible in the unit being constructed.

Finally, on 7 May, about one and a half month before the implementation, when Ms Hou had the drafts of materials ready, I provided comments which included an addition of a final activity for students to reflect on the unit at the end of the lesson and the replacement of the selected videos based on ones that I identified. Mutual support played a role here as in the previous Excerpts (2, 3-1, and 3-2). These analyses made visible that while the teacher relied on me for feedback, I depended on her judgment on the suitability of revisions. Having in mind that the teacher had over 20 years' teaching experience and that she was under the pressure of time to complete teaching her regular lessons while working with me on this research, I consciously attended to my language when sharing my thoughts on the drafts.

The analyses presented in this section showed that in tracing the developing process, I was able to provide evidence that the lesson schedule was flexible, not fixed. A fixed schedule of events for when to start the first stage of the MEC was not decided until much later during the implementation process. Further, through our dialogue, I was informed that on the original dates when the unit was planned to be implemented, something else occupied those dates. During this period, some 
materials were also revised, and some were added. On the $14^{\text {th }}$ of June, we finalised the materials.

The analyses of the Design stage presented above made visible the multiple forms of our collaboration, i.e. text-based and face-face, the length of completing each action, the agreements and disagreements emerged from our discussions, and the ways of casting doubts on fresh ideas, i.e. drawing on our personal experience. These analyses made visible issues for consideration in further research and development processes, including issues of positionality, i.e. a facilitator/guide and an implementer possibly contributing to decision-making, as well as the challenges encountered by both in different tasks and contexts.

\section{EXAMINING IMPLEMENTATION PROCESSES: A MICROETHNOGRAPHIC ANALYSIS}

In this section, I present the processes of entry into the class and data collection during the implementation stage of this collaborative project. The implementation of the unit on Animals and zoos with Should we have zoos? as the prompt question was carried out in mid-June. We spent a lesson in each of three stages which were carried out consecutively on the same day. Ms Hou was the instructor of the class as usual, while I joined the class as a participant observer, an essential role in an ethnographic study (Spradley, 1980). In this role, I was allowed to walk around the classroom, interact with students, answer students' questions during activities, and examine their development of ideas and works.

During all of the three stages, I observed that classroom language was delivered in English, e.g. "Eyes on me," "Share your ideas," "Are you ready?" while the rest of the lessons were conducted by Ms Hou in both English and Mandarin to facilitate students' understanding of the content in the CLIL lesson. During discussions, students were allowed to speak and write in English, Mandarin and Zhuyin (Mandarin phonetic symbols), although most of the group activities were engaged in the students' L1, Mandarin. This process of language choice and use indicates that neither the teacher nor I limited the medium of instruction or students' use of language with the teacher and among peers to English but rather supported communication about content.

This decision was based on our understanding that students in Taiwan are not given official or formal English lessons until Grade 3, leading to the participating students' limited foundation in English literacy. Theoretically and pragmatically, therefore, there is a gap between students' L1 and English literacy when they are 
engaged in critical discussions (LUK \& LIN, 2015). Reaching this agreement with Ms Hou was rather easy. Rather than constraining herself to monolingual ideologies heavily influenced by the theory of second language acquisition (KRASHEN, 1981), Ms Hou acknowledged the potential of L1 in CLIL lessons, especially when she considered that students needed to be encouraged to discuss social issues.

In Stage 2, when Ms Hou engaged students in reading, her approach was quite different from how the MEC was explained previously. Her goal of reaching this stage was to train students to read, by performing the target skills of "identifying keywords, accessing information and expressing opinions" (Ms Hou), rather than performing genre analysis. The purpose of engaging students in reading the given articles, therefore, was to provide different viewpoints on one topic. In other words, reading was done for expanding perspectives, not for acquiring new vocabulary words or sentence patterns.

This aspect caused a challenge for me as a researcher who has studied and decided on the use of the MEC framework. The reality, however, was that the Grade 4 English textbooks did not include any reading passage; what students read was a dialogue often presented in speech bubbles in each lesson. As Ms Hou pointed, "At the primary level, the textbooks were designed based on topics which altogether were designed into a dialogue." Therefore, students had been learning to read and comprehend single/short sentences without connectives. Asking students to read a paragraph in English, as we decided, would be a massive leap from their current level of the reading process, let alone an extended text in English. With this notion in mind, we targeted articles (texts) in their L1. They were chosen, shared with, acknowledged and appreciated by Ms Hou as captured in the following: "The articles you found were awesome! How could you be so good at it?" for the chosen articles' diverse perspectives on the issue of whether zoos should exist.

As indicated in the previous sections on design, analysis and collaborative processes, I made compromises along this research journey by incorporating the teacher's perspectives and explanations that were framed by her understandings of the students in this particular context and the official textbooks. Although, what, and to what, degree we could deviate from the design and implementation of official CLIL materials provided to the teacher and students remained a question that could not be solved simply by referring to a theory or an experience, this researcher-teacher collaborative research team, by adopting IE with event mapping and levels of analysis, shed light on our decision-making process and supported deeper understandings of this dynamic and developing initiative. In this way, research-design-development processes were central to supporting the selection 
and construction of materials, and the implementation processes; they were not separate processes but rather integrated processes in ways that mirror and/or modify the proposed CLIL and MEC processes.

\section{ANALYSING STUDENTS' UNDERSTANDING}

As shown in Figure 4, in the final stage, students were guided to create comic strips, and students were required to complete this work in the target language. To guide students in this stage, Ms Hou prepared question prompts along with an example and a word bank containing words for students' choices or as a reference. As indicated in Figure 4, each question prompt was followed by an answer. The target words, e.g. like and want, were shown in different colours. When listing the English words about colours in the word bank, Ms Hou deliberately changed the font colours based on what those words imply.

\begin{tabular}{|c|c|}
\hline \multicolumn{2}{|c|}{ Speak for the Animat } \\
\hline What animal are you? & I'm an elephant \\
\hline What can you do? & I can stomp. \\
\hline $\begin{array}{l}\text { What color are you ? } \\
\text { How do you look? }\end{array}$ & I'm big and gra \\
\hline Where do you like to live? & want to live in th \\
\hline Why? & $\begin{array}{l}\text { I can't find food ar } \\
\text { it's safe in the zoo }\end{array}$ \\
\hline \multicolumn{2}{|c|}{ \$ Speak for the Animat of } \\
\hline \multicolumn{2}{|c|}{$\begin{array}{l}\text { climb, dance, fly, jump, run, slither, swim, swing, } \\
\text { waddle, walk, }\end{array}$} \\
\hline \multicolumn{2}{|c|}{$\begin{array}{l}\text { red, orange, , green, blue, black, white, } \\
\text { gray(grey), brown, }\end{array}$} \\
\hline \multicolumn{2}{|c|}{ big, small, long, short, tall } \\
\hline \multicolumn{2}{|c|}{ zoo, wild, nature, } \\
\hline \multicolumn{2}{|c|}{ hungry, safe, free, hunter, } \\
\hline
\end{tabular}

Figure 4. The question prompts and the word bank prepared for guiding students to complete the comic strips 
The analysis of her process in this stage showed that the teacher was confident in, and familiar with, preparing the materials in the format that she thought could be most accessible and friendly to her students, i.e. selecting a font, deciding a font size, organising the sentences into blocks, changing the colours of texts consciously and organising the layout.

During the implementation stage, I assumed multiple roles: as a researcher, who observed Ms Hou's lessons; as a facilitator providing support for the teacher; and as ethnographer-as-learner (GREEN ET AL, 2012). The multiple roles that I took up led to a process for this research that was collaborative, horizontal and reciprocal. From this perspective, this collaboration was made possible based on mutual respect for and recognition of personal and professional knowledge as well as by my decision from the beginning of this process not to intervene in the classroom processes. This latter decision was, as presented in previous sections, designed to develop a co-collaborative process, and to the integration of an ethnographic approach that guided me in stepping back from the known (e.g. HEATH, 1982 HEATH \& STREET, 2008; GREEN ET AL, 2012).

\section{STUDENTS' PERFORMANCE IN THE CLIL LESSON}

In this section, I present analyses of students' performance which the teacher deemed as "excellent," in that most of them achieved the language learning outcomes-those listed under Lesson 4, and that they presented viewpoints from different angles.

I'm really glad that my children did follow the lessons. They performed quite well, especially as the $4^{\text {th }}$ Graders. Look at their writing. Their opinions were great, so to me, we decided on a very good topic. Basically, kids know about animals and have been to zoos, but they've never... In fact, what we did was invite them to look at an issue from different perspectives, from animals' viewpoints, which I think is very important. The kids actually, as they are still young, tend to see things starting with I, I, I, I.

This retrospective comment demonstrates Ms Hou's observation of the changes in students. From a self-centred way of seeing the world, students started embracing the act of caring about one issue from the perspective of animals, and perhaps the other people in the future. Figures 5 and 6 are the comic strips created by two students that illustrate their language and literacy processes, as well as their developing content understandings. 


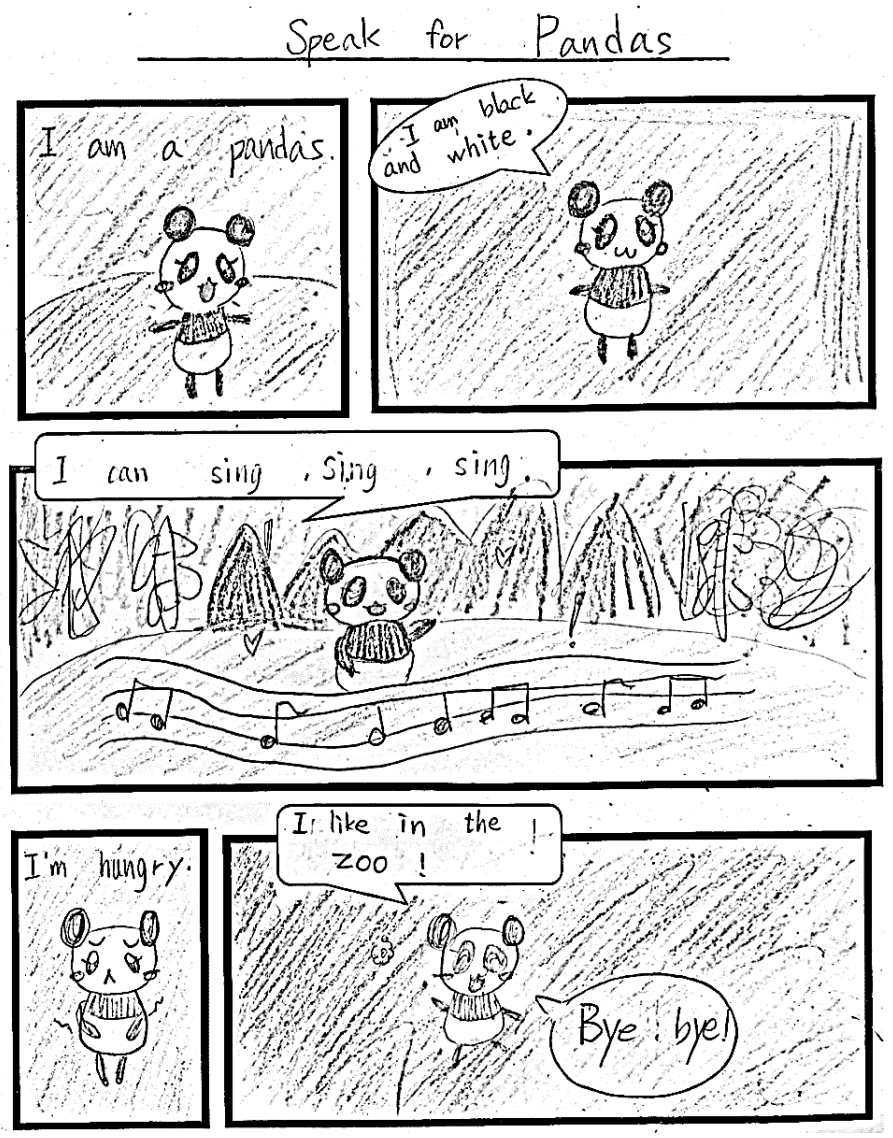

Figure 5. A sample work indicating living in the zoo is the student's preference

A multi-modal analysis of Figure 5, makes visible that the student tried speaking for pandas, a process that drew on the approach to text design described by Ms Hou in a previous section and an approach appropriate to comic book formats. The student was able to state from which animal's point of view he was speaking. He also successfully described this animal regarding its colour and ability. For example, he created a marked contrast in representing the panda as singing happily in a forest but as also becoming hungry. This comic then ends with a statement that this panda likes (living) in the zoo. Interestingly, this student did not specify the reason for why a zoo was chosen, but it could be inferred that he made the decision thinking that living in a forest could lead to hunger while living in the zoo could be provided with food when he was hungry. 
On the other hand, Figure 6 demonstrates a different opinion. As indicated across the storyline and drawings in Figure 6, the student spoke from the perspective of a bear with an actual name. He was also able to describe the bear in simple sentences regarding the bear's size and "skills." A reason for his final choice was not given, but the concept of bome was brought up as a place where this bear should belong.

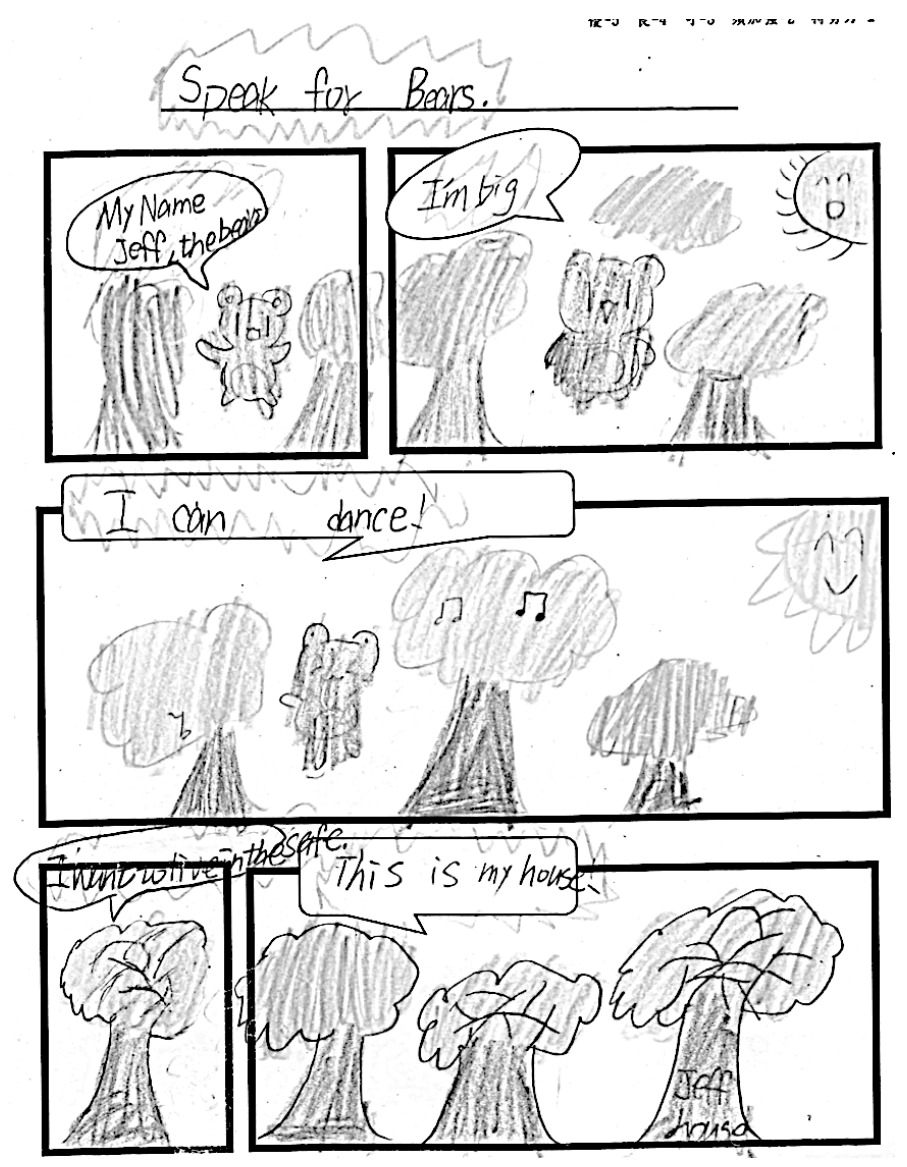

Figure 6. A sample work indicating not living in the zoo is the student's preference

It is noteworthy that when Ms Hou and I worried about how students with limited English proficiency could explain their rationale of choice, the findings provide evidence that students were able to communicate their decisions, given the circumstance that they are not limited to a single modality. Lin's (2015) concept of trans-semiotising supports this interpretation. Lin frames different semiotics, visuals 
being one of them, as an important part of meaning-making. This notion supports what the results have shown in this study. As shown in Figures 5 and 6, while multiple modalities can be a useful practice for instructions, it can also be a meaningful way for students to convey their messages.

This series of analyses demonstrate how welcoming the usage of multiple semiotics is helpful, particularly for students with emerging English skills. While it may seem a challenge at first to integrate social issues as the content, rather than topics for daily communications, into English lessons, students in this study were able to demonstrate their potential understandings and knowledge of the content and language in the dialogic processes that they created for the animals and the visuals created by themselves that contextualize the language and interactions.

\section{THE IMPLEMENTATION OF A UNIT ON ANIMALS AND ZOOS USING THE MEC}

In the previous sections, I have unfolded the collaborative design and implementation of the curricular approach that Ms Hou and I constructed. My goal in this section is to extend the understanding of the processes undertaken in this study that led to successful student participation and performance. By focusing the analysis in this section on implementation as the focal event for displaying the next level of event mapping, I trace the sources, actions and decisions that supported students' performances in this CLIL-based unit. The analyses aim to uncover the students' processes of engagement with our materials, specifically how Ms Hou's instructional processes led to their process of creating opportunities for critical engagement, and to examine whether students' perspectives, engagement, practices, activities and responses during the CLIL lessons support the decisions taken by Ms Hou and me.

To achieve these goals, I constructed a new event map to make transparent the levels of design and actions that led to, as well as during, the implementation stage. As (re)presented in Figure 7, three stages of developing the materials following the MEC approach were identified. Under each stage, each phase, sequences/actions/ activities and students' corresponding responses are recorded for analysis. Each phase reflects the condition that Ms Hou made clear-cut transitions from one stage to another as students demonstrated that they were developing the understandings proposed in the phase of activity. As indicated in Figure 7, to complete each phase, Ms Hou signalled different activities and used different actions to initiate each part of the lesson. To identify the steps that she framed with students, I identified a series of sequential acts that constituted each activity. Finally, an analysis of 
students' overall responses to each phase was developed to make visible changes in students' critical awareness. Particular phases are accompanied by the frames grabbed from videos to provide contextual clues for readers to better understand what was happening in during those phases in that context.

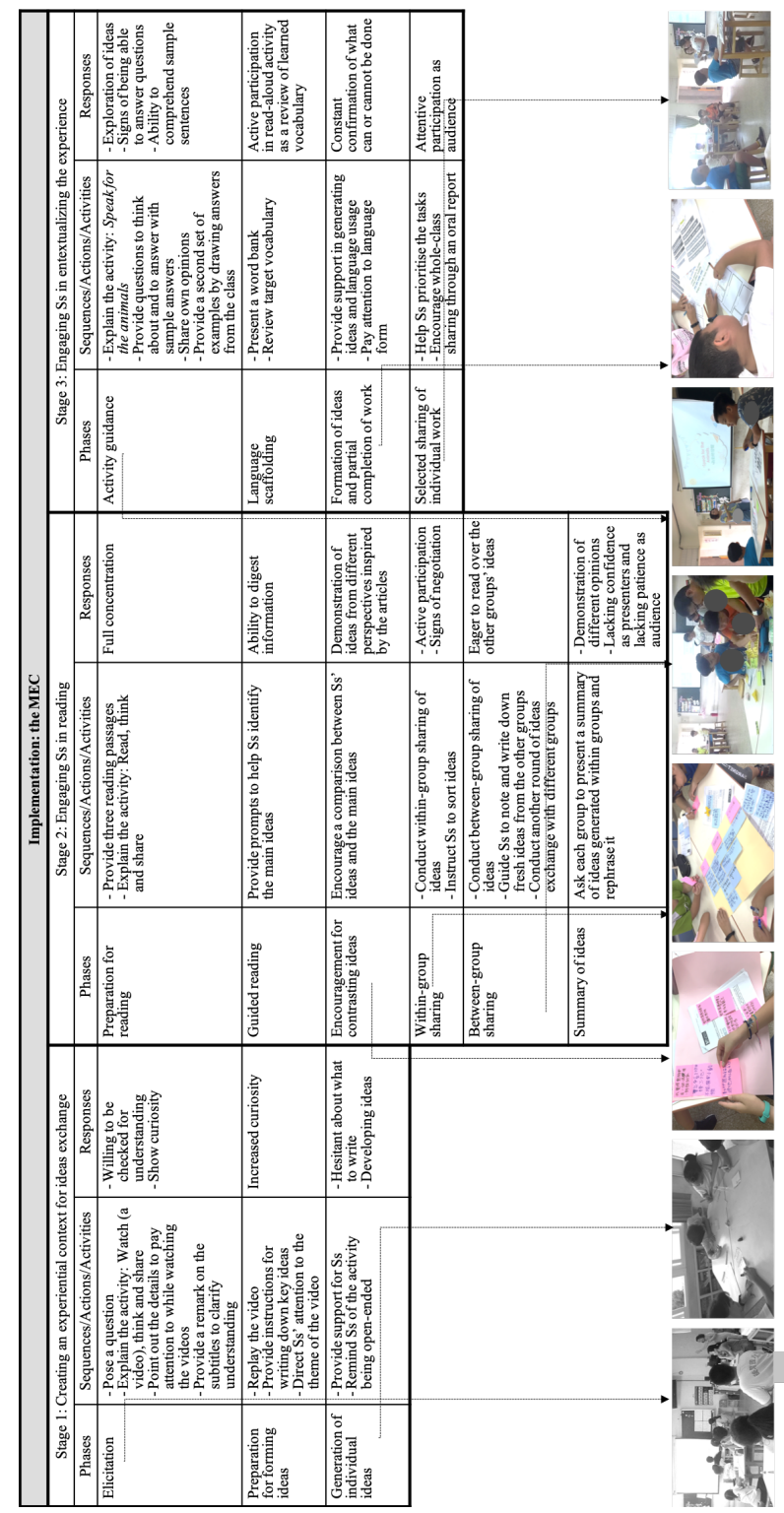

Figure 7. Event map of implementing a unit using the MEC 


\section{ANALYSING STAGE 1: CREATING AN EXPERIENTIAL CONTEXT FOR IDEAS EXCHANGE}

Stage 1 followed Ms Hou's regular English lesson in which she was helping her students review the target vocabulary presented in Lesson 4 through animal riddles. Immediately following the animal riddles activity, Ms Hou posed a question to the class: Should we bave roos? This stage began with an explanation for watching a video. To initiate this stage, Ms Hou also presented students with the procedure they would undergo: watch a video, think about some ideas and share their ideas with their peers. My observation notes indicated that students were attentive and willing to answer Ms Hou's questions while displaying some level of curiosity. The video that was presented to students was one that I had identified and Ms Hou had accepted. It was a short video clip lasting about 2 minutes in the form of dubbed animation with Chinese subtitles.

As indicated in Figure 7, in the second phase, Ms Hou provided the students with a second chance to watch the video while instructing them how they could prepare themselves for the next activity. Analysis of the video record showed that students' curiosity and engagement increased with a clearer idea of what they needed to do next. After watching the video twice, in the third phase, based on the analysis of steps (re)presented in Figure 7, the students were then requested to write down the crucial messages or ideas of the video they just watched, as well as their ideas in the Information Exchange activity. Analysis of the language used in giving instructions showed that the instructions were presented in Chinese, while the oral explanations were given in both Chinese and English.

During this activity, both Ms Hou and I walked around the classroom to see how students progressed. Through this process, we learned that at the beginning of this phase of activity, the students were hesitant about what to write, a process that we viewed as confirming that students were looking for a set of correct answers, the process promoted in previous years. As the aim of this unit was to integrate social issues with English lessons for students to exercise critical awareness, Ms Hou occasionally reminded the class that there were no right or wrong answers and that the expressions were not limited to English but open to Chinese and phonetic symbols (if they had difficulty writing their ideas in English or writing the Chinese characters of certain words).

To explain students' hesitation further, I returned to the data and revisited the dual goals of CLIL (COYLE, 2008). As indicated previously, the generation of ideas for the texts by students could be understood as a challenge to past practices in Grades 1-3, given that Ms Hou previously stated that students were taught and 
trained to look for the right answer. On the other hand, students' awareness that they were taking an English lesson at that moment led them to reconfirm with the teacher whether they needed to write down everything in English. Analysis of the videos and my fieldnotes led me to understand further Ms Hou's emphasis on students' flexibility, i.e. they could communicate their understandings in any language and with any ideas that came to mind. As indicated previously, and (re) presented in the analysis of the comic text, the students begin developing and noting down their thoughts through multi-model processes.

\section{ANALYSING STAGE 2: ENGAGING STUDENTS IN READING}

As indicated in Figure 7, the second stage of the MEC emphasised the importance of reading and note-making with students, regardless of everyday or academic texts or L1 or L2 texts. Similar to the previous stage, the teacher began with the preparation phase, providing the students with the materials and clear instructions to follow. All the reading passages were in Mandarin, which could be why the class was able to pay their full concentration in this phase. Next, Ms Hou intervened as a guide to check students' understanding. She provided some prompts to guide them in locating the main idea of each article. Once it was confirmed that the class got hold of the essence of each article, Ms Hou moved on to the next activity, which was similar to the one done after watching the video. Since it was the students' second time writing down ideas, and that they were equipped with the resources of ideas from the articles, most of them were able to complete this task with more than one idea, neatly arranged and pasted into a column.

With the ideas in hand, students were assigned the within-group sharing activity, in which they needed to talk about their ideas with their group mates and sort their thoughts into particular categories, i.e. arrange similar concepts into the same columns and begin those columns with the keywords written on the memo note in a different colour. During this activity, we saw students' active participation, accompanied by signs of negotiations for which ideas belonged to the same sort. Figure 8 shows a sample group work with an English translation below the work. This phase was followed by two rounds of between-group sharing, which requested the students to mingle with members from the other groups to look over and examine any similarity or difference. To end this stage, Ms Hou tried summarising students' ideas and had each group stand up to present their summary of ideas. However, students showed a lack of confidence as presenters and a lack of patience 
as the audience. While students were able to generate and organise their ideas, it was more feasible in groups than in a whole-class setting.

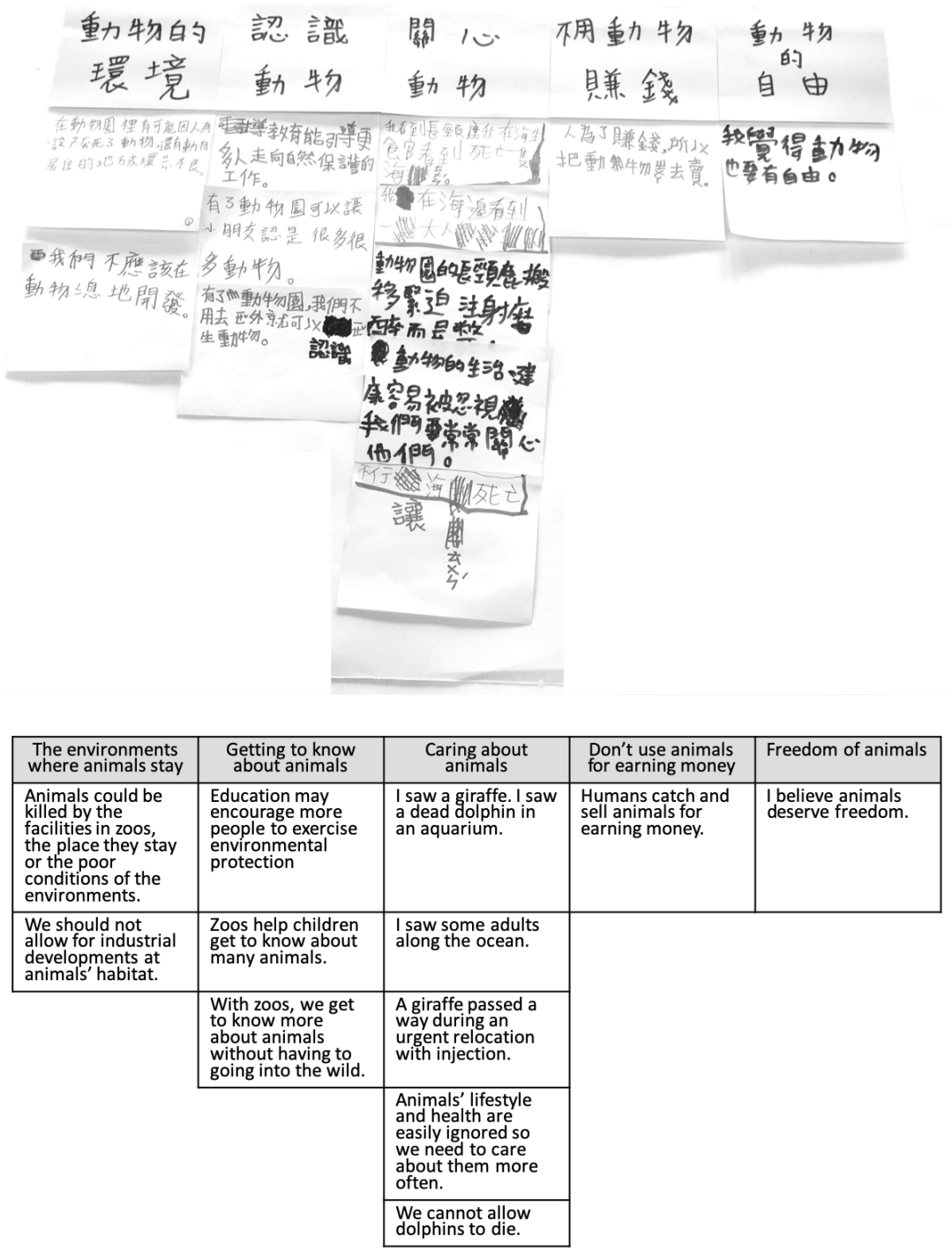

Figure 8. Sample work of discussing, gathering and sorting ideas within a group

In Figure 8, I provide evidence of how Ms Hou treated this stage by mapping the developing steps, actions and activities. This stage, therefore, maps the provision of content input for students, rather than a stage for the teaching of reading or paragraph analysis. This stage was carried out rather differently from 
what was elaborated in Lin's $(2015,2016)$ work. With this way of looking at the reading activity, Ms Hou focused on the delivery of content and the exchange of ideas. Therefore, she spent most of the time on encouraging students to write down their opinions based on the three articles they were given to read and based on the sharing of ideas both within and between groups. The purpose was to provide students with as many aspects to look into the issue of establishing a zoo as possible. With many ideas in mind, Ms Hou then asked students to sort them out as a team by categorising the similar ones under one category with a name. Similarly, there was barely any limitation to the usage of language in this stage.

\section{ANALYSING STAGE 3: ENGAGING STUDENTS IN ENTEXTUALIZING THE EXPERIENCE}

As indicated in Figure 7, after the collection of various ideas from group mates and classmates, students had to complete a task individually. The activity in this stage was named Speak for the animal. Ms Hou began, as usual, with a phase for explaining how to complete that task. Question prompts were provided to guide students' completion of the work. The teacher's own opinions were also shared as sample answers. Students were guided to explore their, and the other's ideas discussed earlier. They seemed to be following the teacher's explanation for this activity. In the next phase, Ms Hou drew students' attention to language points. By bringing the students' attention to those question prompts (see Figure 4), the teacher not only provided language support but also took it as a chance to review the target sentence patterns and vocabulary words with the students. Students repeated after the teacher in this read-aloud activity serving as a guide and as a review. This seamless link was what we hoped to achieve- the language was used for demonstrating what has been learned in English lessons and for showcasing content knowledge drawing on all those ideas collected through reading articles and sharing ideas.

As described previously, to complete this task, students had to select an animal and speak on behalf of the chosen animal about whether living in a zoo was the preference. Thus, in the next phase, students formed and organised ideas by utilising the vocabulary words and sentence patterns to fill in the speech bubbles from the perspective of an animal, along with their coloured drawings to create their comic strips. Again, the teacher and I walked around the classroom to provide support both in terms of the content and the language. It was found Ms Hou paid more attention to the form of language (BLOOM \& LAHEY, 1978) while checking 
on students' progress of work. She pointed out at students' work regarding where the punctuation mark, a period was missing, which word should have been plural, which letter should have been capitalised, etc., indicating that in an English lesson setting, we adopted the soft CLIL approach (BENTLEY, 2010).

Observations during this stage also made visible that towards the end of the lesson, some students were struggling to complete the work. Analysis of my records and the video showed that Ms Hou intervened to support students in completing the task by proposing to students that they prioritise the tasks, e.g. complete a sketch and determine the lines in the speech bubbles, rather than colouring them. Before ending the class, Ms Hou encouraged whole class sharing by inviting students to present their works in front of the class orally. The analysis here illustrates the resources, support and encouragement students received that helped them construct their comic strip. The analysis further confirms how our collaboration also played a role in shaping students' products. The analyses presented in this section also confirmed my understanding of how multimodality is a powerful tool to support students in both learning content and developing their communicative abilities in both their L1 and L2 languages. That is, the use of visual images (HE, LAI, \& LIN, 2016) in these lessons facilitated not only students' learning content but also the students' expression of critical awareness in a language they were unfamiliar with.

\section{CLOSING COMMENTS AND FUTURE DIRECTIONS}

In tracing the developments as well as our collaborative decisions across stages of the developing collaborative project, what my co-researcher and I learned is captured in the following excerpt from a reflection session at the end of this study, which occurred right after the end of this unit, on 26 June. In that reflection period, we discussed our overall impression of this collaboration, from the design to the implementation. We began by debriefing the overall process of design and implementation. Ms Hou's understanding of what was accomplished through this collaborative opportunity is indicated in the following excerpt from our reflections:

Honestly, I do think that I've gained much. It occurs to me that the next time I observe my students' learning experiences, I will do so from more dynamic lenses and create a much broader space. I think that to me, I will be more flexible and tolerant.

In this excerpt, Ms Hou echoes the findings obtained from the analyses presented throughout that showed mutual learning as an essential part of this 
journey. This comment shows how the teacher positioned herself as not only a giver, but also a receiver, the attitude of which helped shape my learning and research process as well as an understanding of the complex challenges faced by teachers and researchers seeking overtime understandings of the implementation of this reform initiative. The need for collaborative teams was further captured in the following statement by Ms Hou, who stated that I, in my role as a consultant researcher, provided significant, unanticipated and valued levels of support in the design process of materials.

By creating a collaborative team approach to ethnographic analysis, I was able to map and create texts for analysis of the sequences of actions taken by the teacher and students' and their responses to these actions across time. I was also able to explore how this researcher-teacher collaboration played a role in shaping and supporting students' performance in a CLIL unit. Although as a researcher, I had little direct face-to-face interaction with the participating students, the multiple levels of analyses presented in this study demonstrated a theoretically and conceptually grounded approach, IE, to tracing the impact on students' changes in the understandings of tasks and the roots of their performance processes. Additionally, the multiple levels of analysis framed ways in which, as a researcher and a consultant, I contributed to, and learned from, the developing processes for students through the co-collaboration that we constructed. In this way, I made visible a potential approach to closing the gap between research and practice, and design and implementation.

As He and Lin (2018, p. 186) proposed, teacher education for CLIL is "a collaborative, dynamic, and dialogic process." The finding of this study has strengthened this argument not only with research findings but mainly with the "unboxing" of what happened between the participating teacher and me that contributed to every instance of decision-making. Based on the goal of making visible the invisible and extra-ordinary the ordinary central to an IE logic-of-inquiry (CASTANHEIRA ET AL., 2000), during my research journey, I made transparent the steps, actions, and decisions that made this collaboration and communication a basis for ongoing, iterative and two-way processes central to learning to transform particular elements of existing curriculum to address policy reforms. While the key events constructed for students were identified and discussed in this paper, this study only reports the development of a single unit of CLIL instruction. More research needs to be done to open up such social spaces for critical issues to be discussed at primary schools. Next steps will need to trace this process across other units developed by Ms Hou and explore how and if other teachers' processes and 
decisions confirm her approach to integrating CLIL in their ongoing curriculum. Such studies will also want to examine how teacher professional development is conducted as well as how ethnographic research can provide warranted evidence of how reforms can and are being undertaken. This approach, as demonstrated in the multiple phases of analysis will require the development of collaborative teams, where both learn what is required to support the goals of globalization for both Taiwanese and international students across levels of schooling.

\section{REFERENCES}

AGAR, M. (2006). An ethnography by any other name... Forum: Qualitative Social Research. v. 7, no 4. Retrieved from: http://www.qualitative-research.net/index.php/fqs/article/ viewFile/177/396

AIELLO, J.; DI MARTINO, E.; DI SABATO, B. (2017). Preparing teachers in Italy for CLIL: reflections on assessment, language proficiency and willingness to communicate. International Journal of Bilingual Education and Bilingualism. v. 20, $\mathrm{n}^{\circ} 1$, pp. 69-83.

BENTLEY, K. (2010). The TKT course CLIL module. Cambridge, UK: Cambridge University Press.

BLOOM, L. AND LAHEY, M. (1978). Language development and language disorders. New York: John Wiley \& Sons.

BROWN, A. L. (1992). Design experiments: Theoretical and methodological challenges in creating complex interventions in classroom settings. The Journal of the Learning Sciences. v. 2, $\mathrm{n}^{\mathrm{O}} 2$, pp. 141-178.

CASTANHEIRA, M. L.; CRAWFORD, T.; DIXON, C. N.; GREEN, J. L. (2000). Interactional ethnography: An approach to studying the social construction of literate practices. Linguistics and education. v. 11, $\mathrm{n}^{\circ}$ 4, pp. 353-400.

CHRISTIE, F.; MARTIN, J. R. (eds.). (2005). Genre and institutions: Social processes in the workplace and school. New York: Continuum.

COLEMAN, J. A. (2006). English-medium teaching in European higher education. Language teaching. v. $39, \mathrm{n}^{\circ} 1$, pp. 1-14. 
COLLINS, A.; JOSEPH, D.; BIELACZYC, K. (2004). Design research: Theoretical and methodological issues. The Journal of the learning sciences. v. $13, \mathrm{n}^{\mathrm{O}} 1, \mathrm{pp} .15-42$.

COYLE, D. 2008. 'CLIL-A pedagogical approach from the European perspective. In: Van Dusen-Scholl, N.; Hornberger N. H. (eds), Encyclopedia of language and education. New York: Springer Science + Business Media LLC., pp. 97-111.

COYLE, D.; HOOD, P.; MARSH, D. (2010). Content and Language Integrated Learning. Cambridge, UK: Cambridge University Press.

CUMMINS, J. (1981). Empirical and theoretical underpinnings of bilingual education. Journal of education. v. 163, nº 1, pp. 16-29.

EDELSON, D. C. (2002). Design research: What we learn when we engage in design. The Journal of the Learning sciences. v. 11, $\mathrm{n}^{\mathrm{O}} 1$, pp. 105-121.

ESCOBAR URMENETA, C. (2013). Learning to become a CLIL teacher: teaching, reflection and professional development. International Journal of Bilingual Education and Bilingualism. v. 16, n 3 , pp. 334-353.

GREEN, J. L.; DIXON, C. N.; ZAHARLICK, A. (2005). Ethnography as a logic of inquiry. In: J. Flood; D. Lapp; J. Jensen; J. Squire (eds.), Handbook for research on teaching the English language arts. Mahwah, NJ: Lawrence Erlbaum Associates, Inc., pp. 201-224.

GREEN, J. L.; SKUKAUSKAITE, A.; BAKER, W. D. (2012). Ethnography as epistemology: An introduction to education ethnography. In: Arthur, J.; Waring, M.; Coe, R.; Hedges, L. V. (eds), Research methods and methodologies in education. London: Sage, pp. 309-321.

HALLIDAY, M. A. (1993). Towards a language-based theory of learning. Linguistics and education. v. 5, no 2, pp. 93-116.

HEATH, S. B. (1982). Ethnography in education: Defining the essential. In: Gilmore, P.; Glatthorn, A. (eds). Children in and out of school. Washington, D.C.: Center for Applied Linguistics, pp. 33-58).

HEATH, S. B.; STREET, B. (2008). On etbnograpby: Approaches to language and literacy research. NY: Teachers College Press.

HE, P.; LIN, A. M. Y. (2018). Becoming a "language-aware" content teacher. Journal of Immersion and Content-Based Language Education. v. 6, $\mathrm{n}^{\circ}$ 2, pp. 162-188. 
HE, P.; LAI, H.; LIN, A. M. Y. (2016). Translanguaging in a multimodal mathematics presentation. In: Mazak, C. M.; Carroll, K. S. (eds.), Translanguaging in bigher education: Beyond monolingual ideologies. Bristol, UK: Multilingual Matters., pp. 91-120.

HUANG, Y. P. (2014). Teaching content via English: A qualitative case study of Taiwanese university instructors' instruction. Foreign Language Studies, v. 20, pp. 27-62.

IKEDA, M. (2013). Does CLIL work for Japanese secondary school students? Potential for the 'weak' version of CLIL. International CLIL Research Journal, v. 2, n 1, pp. 31-43.

JOHNSON, D. W., \& JOHNSON, R. (1989). Cooperation and competition: Theory and research. Edina, MN: Interaction Book Company.

KACHRU, B. B. (1992). The other tongue: English across cultures. Urbana: University of Illinois Press.

KARABASSOVA, L. (2018). Teachers' conceptualization of content and language integrated learning (CLIL): evidence from a trilingual context. International Journal of Bilingual Education and Bilingualism, pp. 1-13. https://doi.org/10.1080/13670050.2018. 1550048

KELLY, G. J.; CHEN, C. (1999). The sound of music: Constructing science as sociocultural practices through oral and written discourse. Journal of Research in Science Teaching: The Official Journal of the National Association for Research in Science Teaching. v. 36, $\mathrm{n}^{\circ} 8$, pp. 883-915.

KRASHEN, S. (1981). Second language acquisition and second language learning. Oxford: Pergamon Press.

LEE, H. Y.; YANG, S. R. (2018). Tainan blazes trail in making English Taiwan's $2^{\text {nd }}$ official language. Focus Taiwan, 29 January. Retrieved from: http://focustaiwan.tw/news/ aftr/201801290011.aspx

LIN, A. M. Y. (2015). Conceptualising the potential role of L1 in CLIL. Language, Culture and Curriculum. v. 28, n ${ }^{\circ}$, pp. 74-89.

LIN, A. M. Y. (2016). Language across the curriculum \& CLIL in English as an Additional Language (EAL) contexts: Theory and practice. Singapore: Springer.

LO, Y. Y. (2019). Development of the beliefs and language awareness of content subject teachers in CLIL: does professional development help? International Journal of Bilingual Education and Bilingualism. v. 22, $\mathrm{n}^{\circ} 7$, pp. 818-832. 
LUK, J., \& LIN, A. (2015). Voices without words: Doing critical literate talk in English as a second language. TESOL Quarterly. v. 49, nº 1, pp. 67-91.

MERCER, N. (1995). The guided construction of knowledge: Talk amongst teachers and learners. Clevedon: Multilingual Matters.

PEREZ CAÑADO, M. L. (2016a). Are teachers ready for CLIL? Evidence from a European study. European Journal of Teacher Education. v. 39, n 2, pp. 202-221.

PÉREZ CAÑADO, M. L. (2016b). Teacher training needs for bilingual education: Inservice teacher perceptions. International Journal of Bilingual Education and Bilingualism. $\mathrm{v}$. $19, n^{\circ} 3$, pp. 266-295.

ROSE, D.; MARTIN, J. R. (2012). Learning to write, reading to learn: Genre, knowledge and pedagogy in the Sydney School. Bristol: Equinox.

SPRADLEY, J. (1980). Participant observation, New York, NY: Holt, Rinehart and Winston.

STAKE, R. E. (1995). The art of case study research. Thousand Oaks, CA: Sage.

VAN DEN AKKER, J. GRAVEMEIJER, K.; MCKENNEY, S.; NIEVEEN, N. (eds.). (2006). Educational design research. London: Routledge.

YEH, H. N. (2016). Prospects of English textbooks for elementary and high schools in view of draft curriculum guidelines for twelve-year basic education. Journal of Textbook Research, v. 9, n 3, pp. 143-168.

Recebido: 21/10/2019

Aceito: 22/12/2019

Publicado: 2/03/2020 